\title{
Children's Bodies in British Columbia's Child Care Regulations: A Critical Discourse Analysis
}

\author{
Connie M. Antonsen
}

Connie M. Antonsen has worked as an early childhood educator on Vancouver Island for many years. She is currently a sessional instructor, research assistant, and tutor in the School of Child and Youth Care at the University of Victoria, located on the traditional territories of Lekwungen-speaking peoples. This paper began as part of her master's project that asks how postfoundational empirical research understands children's bodies and questions conformity while unpacking the institutionalized practices that control bodies, for the purpose of reimagining new possibilities in early childhood education. Email: cmant@uvic.ca

This paper contributes to discussions that challenge dominant thinking by deeply reflecting on children's bodies as they are depicted in British Columbia's Child Care Licensing Regulations. Using critical discourse analysis, the author highlights how techniques of power are embedded in this particular document by examining how power works to regulate, normalize, and discipline children's bodies in early childhood education. The paper describes how this government policy works to create and sustain common child care practices by exploring four questions about the organization of the regulations document to open alternative conversations about young bodies in early childhood practices.

Key words: children's bodies; early childhood education; deconstructing developmental psychology; techniques of power; child care licensing regulations

questions adapted from Pacini-Ketchabaw (2005):

1. What assumptions have been made about children's bodies through the organization of the regulations?

2. How have techniques of power worked to shape bodies through the discourses present in the regulations?

3. What social, cultural, and contextual conditions relating to children's bodies are embedded in the regulations?

4. What issues have the discourses in the regulations claimed to resolve?

I propose that unpacking the position that children's bodies occupy within the regulations will contribute to
Power functions at the level of the body, at the micro level ... [by] reach[ing] into the very grain of individuals, touch[ing] their bodies and insert[ing] itself into their action and attitudes, their discourses, learning processes and everyday lives.... Power also involves resistance.... This resistance plays an important role in legitimizing the discourses around the care and education of young children. (PaciniKetchabaw, Nxumalo, Kocher, Elliot, \& Sanchez, 2015, p. 209, drawing from Foucault, 1977, 1978; emphasis in original)

Furthering discussions that relate to children's bodies in early childhood education (Burke \& Duncan, 2015; Millei \& Cliff, 2014), this paper challenges normative thinking by reflecting on children's bodies as they are depicted in British Columbia's Child Care Licensing Regulations (BC Laws, 2016), referred to in this article as "the regulations." Using critical discourse analysis, I point out how techniques of power are embedded in this particular document by deconstructing it through an examination of how it works to regulate, normalize, and discipline children's bodies in early childhood education. I describe how this government policy has worked to create and sustain what are considered to be common child care practices by exploring the following four 
deeper understandings of how early childhood education (ECE) is acknowledged and will open new conversations about young bodies in early childhood practices. Uncovering hidden meanings within regulatory child care texts has benefitted children and families, as well as those who work with them, through consideration of alternative discourses (Moss \& Petrie, 2002; Pacini-Ketchabaw, 2005). To consider alternate discourses in the ECE field, policy documents need to be critically examined (Pacini-Ketchabaw, 2005). My examination of the regulations looks for patterns where I believe discursive thinking begins, as described by Sevenhuijsen (1998):

Policy texts and legal texts are, after all, "stories in themselves": they include patterns of dealing with things, which are often the result of political compromises and discursive traditions. They often contain fixed patterns of speaking and judging, but they can also open up unexpected discursive spaces, where new forms of thinking and judging can start. (p. 30)

My intention in this article is to look carefully at how power works through the regulations and to highlight deeply held assumptions that work to regulate, normalize, and discipline children's bodies. I engage MacNaughton's (2005) poststructural interpretation of Foucault's $(1977,1978)$ work to consider these practices as workings of power, defining power as a network of discursive relations.

My work questions how early childhood educational practices are entrenched in power that acts on young bodies. I look for examples hidden in the regulations that are understood as "correct" child care practices based on implicit assumptions that have been formed by discourses of developmental psychology and heteronormativity. These discourses work within a regime of truth that prescribes "the right way" to organize bodies. I describe how these governmental circuits of power become deeply enmeshed in disciplinary knowledges that measure practice in terms of technologies (Ashton, 2014). I highlight hidden social, cultural, and contextual conditions in the regulations by making connections about neoliberalism. Leaning on Moss (2014), I define neoliberalism as an influential worldview that claims to explain how to live well using dominant stories of quality, by calculating social transactions of living. I assert that it is through the power of neoliberalism that ideas are transferred into policy texts that shape bodies. For example, I describe how political power gives greater value to some bodies over others. While describing the workings of discursive power, I aim to extend the reconceptualization literature (Cannella, 1997; Dahlberg, Moss, \& Pence, 2013; Kessler \& Swadener, 1992; MacNaughton, 2005; Pacini-Ketchabaw et al., 2015) by opening cracks in the ways of thinking, working, and doing early childhood education.

\section{A theoretical standpoint}

\section{How does regulation work?}

To define the term regulation, I lean on the way MacNaughton (2005) unpacks Foucault's "regimes of truth." These regimes work to control thinking and being by aligning behaviours with political intent. MacNaughton (2005) connects the emergence of what is accepted as truth with Gore's (1993) description of generating an "authoritative consensus about what needs to be done ... and how it should be done" (p. 30). Through the employment of mainstream thought, I perceive "truth" as linked in circular relations with systems of power that produce and sustain it (Foucault, 1977). Once formed, these systems of truth create dominant power, from which discourses emerge that influence knowledge about how early childhood education is supposed to be, based on what is considered to be appropriate or correct knowledge. Ideas that become known as rational, or the common way of thinking, connect powers of neoliberalism with governmentality. This powerful connection provides and promotes a system of ideas that translate into mechanisms or technologies of practice. Thus, regimes of truth work to govern and therefore regulate powerful ideas about what are considered to be desirable ways to think, act, feel, and live. 
Bringing regimes of truth into the realm of child development knowledge, MacNaughton's work thinks with theorists such as Walkerdine, Cannella, and Alloway to describe how the regulation and governing of ideas contribute to what is recognized as the appropriate way to organize young children in educational settings. For example, governments currently issue policy documents as checklists for correctness in working with children (British Columbia Director of Licensing Standards of Practice, 2016), which solidify common attitudes in organizing bodies to live a particular way, such as reducing problems of obesity and screen time.

Many critical ECE researchers and theorists suggest that discourses in developmental psychology have created truths that are commonly used by early childhood educators to determine ways to classify, distribute, and regulate children's bodies (Burke \& Duncan, 2015; Burman, 2008; Cannella, 1997; MacNaughton, 2005; Varga, 2011). According to MacNaughton's (2005) analysis, developmental regimes use "developmentally appropriate education [as] the mark of a good early childhood educator and developmentally inappropriate education marks out a bad early childhood educator" (p. 33). Therefore, developmental regimes of truth have encouraged and confirmed knowledge that prescribes how to do early childhood education correctly.

Additionally, MacNaughton (2005) interprets Foucault's idea of truth as having both political and ethical substance. For example, the behaviour of children's bodies becomes directed by official government-sanctioned truths that are woven together with a system of management that governs what is held to be the most "desirable ways to think, act and feel in, for instance, early childhood institutions" (p. 32). Thus, a system of morality is officially sanctioned that dictates what is considered to be a good or true way to live and what makes the early childhood educator a person who holds ethical substance. The weight of what the regime considers morality thus lies within each educator, who is expected to practice within the boundaries of what the regime considers to be true. For example, rules of behaviour through discourses of developmental psychology are set for children at specific ages and during particular incremental stages of development follow the belief that all children's bodies have similar needs at established times. MacNaughton describes these prescribed truths as having real implications for children's bodies because they work to constrain and dictate the possibilities of what bodies can and cannot do and be. She notes that early childhood educators are positioned as entrusted authority figures who have a responsibility to produce universal bodies in a society that values sameness.

The regulations therefore work to sustain what MacNaughton calls "practices of inclusion and exclusion" (p. 85) that rely on binaries that classify bodies into those that fit a particular mold and those that do not. My analysis interprets the regulations as prescribing behaviour through dominant understandings that create discourses that bring truth from an authority accepted as powerful and knowing and that expect what is understood as the best outcome. This position contrasts with British Columbia's Early Learning Framework (British Columbia, 2008a), which values complexity in learning through relationship, exploration, social responsibility, and diversity.

\section{How does normalization work?}

MacNaughton (2005) takes the idea of privileging some bodies over others and, using Foucault's (1977) description of power as described below, claims that the definition of normalization begins with power-not the kind of power that is understood as forcing one person or group to do something, such as sitting quietly. Rather, MacNaughton explains that,

for Foucault, power is a relationship of struggle (Belsey, 2002) ... over how we use truths and build discourses about normality to produce and regulate ourselves (e.g., our bodies, desires and texts), our relationships and our institutions, especially our production of normality (Alvesson, 2002). (MacNaughton, 2005, p. 27) 
With an abundance of accessible literature that details lists, maps, and instructions of what normal child development looks like, child development can be easily measured and expressed as normal. For instance, a simple Internet search for "measuring normal child development" draws four million results. Growth and development milestones can be accessed on government sites such as HealthLinkBC (2016) to determine if a child's body falls in line with what is considered to be normal.

It seems that over time the social sciences have categorized children's bodies by organizing specified ways to practice early childhood care and education that uphold truths about normal ways to comfort bodies, relate to peers, and concentrate on tasks. For example, comforting a child who experiences sadness can be sanctioned according to a child's age. Truths about a normal child matter, because educators use these truths as they connect with others and manage programs, representing an understanding of the "normal child, the abnormal child, and the delayed child" (MacNaughton, 2005, p. 29). Developmental truths about children's bodies matter, because governments use them to inform their policies as they improve the community's capacity to use data to monitor child development and create effective community-based responses (KSI Research International, 2017).

Therefore, normalization works by "comparing, invoking, requiring, or conforming to a standard that expresses particular truths about, for example, the developing child" (MacNaughton, 2005, p. 31). This happens by observing children's bodies and comparing their routines with what has evolved as discourses of developmentally appropriate practice (DAP) during behaviours such as sleeping, toileting, and eating that shape children's temperament according to what is considered to be normal (Millei \& Cliff, 2014).

\section{How does discipline work?}

To define discipline, I begin with MacNaughton's (2005) use of Foucault's (1984) work to describe the political substance of a regime of truth as a reliance on the practices of power that bring the regime and its truth to life. Embedded in these practices lies the power of rules that organize and discipline behaviour. Drawing on Gore's identification of Foucault's ideas, MacNaughton describes "micropractices of power" (pp. 30-31) that can be used to analyze how daily practices in early childhood education bring truth to life. This is important, because bringing truth to life is how discourses emerge and thus how common thinking is born. These micropractices include surveillance, which disciplines by closely observing from a reference point that follows particular truths. For example, educators who expect to be observed and supervised by others who believe best practices follow developmentally appropriate approaches will comply by bringing a developmental regime of truth to their practice. Exclusion disciplines by using truths to dictate what should be included or excluded, with an understanding that particular ways of being are desirable or undesirable, and by creating a definition of pathology for what is undesirable. Furthermore, an educator will use classification as a means to differentiate between right and wrong amidst groups or individuals in ways such as distribution, which ranks development by organizing bodies into groups according to age or stage of development. Individualization uses truths to separate individuals, for example, separating bodies that are developing normally from those that are not. Totalization uses truths to produce a will to conform, such as following developmental truths to guide decisions about what all children should be capable of doing at a given time. For example, Burke and Duncan (2015) describe Foucault's (1975/1995) focus on the child's body as the site of discipline through which control comes from realizing individual desires are secondary to those of the group. Therefore, discipline is the enactment of what has become known as truths through the use of micropractices of power to govern ourselves and others.

These enactments bring about ethical questions: MacNaughton (2005), leaning on Foucault, describes institutionally produced and approved truths that govern and discipline bodies through discretion about where, what, and how bodies are expressed. Using Feher (1987), MacNaughton (2005) describes the political notion of the body as a 
"battlefield of power relations" (p. 30), yet; on the other hand, ethical questions arise regarding how one's own body is in relationship with itself and how that relationship shifts. Thus, the political substance of a regime of truth entangles with an ethical definition of the relationship of people to their bodies. Millei and Cliff (2014) provide an example of this struggle by describing the supervision of children's bodies in the bathroom as holding political power through the regulation of bodies as the object of critical examination and self-examination in order to cultivate healthy habits and to produce "proper" deeds that fall in line with communicated norms. Thus, ethical implications that explore other possible activities in the context of the bathroom space depend on the relationship children have to their bodies. This unpacking of discipline complexifies ideas about how the educator's view on policy in the bathroom might align or conflict with their own ethical ideas when observing bodies during toileting activities.

Therefore, discipline works in early childhood education through truth that has become knowledge and is therefore sanctioned institutionally to produce an authoritative consensus that guides educators to the point where it is difficult to live in any other way. Once officially accepted, truths work to discipline and govern bodies through techniques and procedures that direct bodies. These neoliberal mechanisms of discursive power manage and govern early childhood education through a system of ethical substance that holds the authority to decide what practices are good/bad and right/wrong for children's bodies. Within this disciplined and polarized regime, developmentally appropriate education has become the mark of a good ECE program.

How does the regulation of bodies take place in the regulations?

Discourses of developmental psychology. The regulations put forward discourses of developmental psychology. Through this lens, children's bodies are universal and therefore need to fall into organized classifications that can be measured by age or stage for the purpose of aligning them into spaces of education and care (Burman, 2008; Dahlberg \& Moss, 2005; MacNaughton, 2005; Moss, 2014). The regulations measure bodies in multiple ways. For example, Section 48.1a states that a licensee must "ensure that each child has healthy food and drink according to Canada's Food Guide." To shape discourses that assume children's bodies need a particular set of nutrients for healthy development, the regulations "promote healthy eating and nutritional habits" (48.1b). Canada's Food Guide (Health Canada 2016) provides a specific course of action by stating what kinds of and how much food and drink children's bodies should consume. Section 48.3a-b of the regulations rationalizes measuring bodies using a scale of age and time spent in care to prescribe adequate amounts of food and drink. This developmental psychology discourse regulates bodies through quantifiable considerations that compare bodies of the same age (Burman, 2008). This regime of power scripts a Euro-Western policy that regulates young bodies by providing nourishment according to one particular knowledge base. In contrast, eating habits that fall outside the clearly set guidelines are considered abnormal for healthy development, and therefore become less desirable. MacNaughton (2005) sees the power to dictate healthy development as a relationship of struggle over how guides are used to enact and confirm "truths" that ensure nutrition for bodies. These truths build discourses about bodies by keeping them in check with particular cultural assumptions about health and safety. This is how discourses work in the regulations to regulate children's bodies.

As Fleer (2003) explains, the organization and hierarchy of developmental discourses privilege bodies that score in desirable ways, such as consuming predetermined amounts of food and drink. Discourses of developmental psychology therefore regulate bodies by classifying them as desirable or undesirable, prioritizing compliant bodies as desirable.

Discourses of compliance. Generally, the regulations are organized according to developmental discourses that refer to a need to follow rule-based programming. Along with setting rules, I notice a discourse of compliance that 
conveys a sense of certainty with the belief that outcomes involving children's bodies can and should be known when rules are followed. For example, Section $44.1 \mathrm{~b}$ requires "a comprehensive and coordinated program of indoor and outdoor activities that is appropriate for the age and development of children in each group. This section holds an implicit assumption that children's bodies need guidance and rule-based programming that follow assumptions based on age and development, even when terms such as "appropriate" are not clearly defined. Dahlberg and Moss (2005) describe practice based on inscribing a list of rules as a deficit-based approach to regulating bodies through an intention to follow authoritative power techniques. Rule-based discourses such as those in the regulations conjure an embedded assumption that bodies need instruction by others to decide what is best for them (Burke \& Duncan, 2015; MacNaughton, Hughes, \& Smith, 2007).

The pattern of expected confirmation and belief in the regulations creates a discourse of compliance by putting educators in a position of upholding developmental truths. When educators believe they are providing excellence in programming by following discourses of compliance, children's bodies are regulated. Thus, the regulations regulate bodies through discourses of compliance that frame thinking that connects good practice with developmental truths that produce certainty through rule-based programming.

Discourses of heteronormativity. The regulations work to regulate bodies through discourses of heteronormativity that privilege dominant attitudes about gender, sexuality, and sexual behaviour. For example, Schedule F.1(b) states that "a licensee who provides overnight care to children ... must ensure that no child over 6 years old is accommodated in a room shared by another child of the opposite sex without direct employee supervision." This single way of knowing children's bodies, defined by preferred, dominant heterosexual gender identities and sexualities, remains hidden in DAP (Pacini-Ketchabaw et al., 2015). Dominant heterosexual gender binaries are confirmed by knowing that a body of one biological sex should not be in the same room overnight with a body of another biological sex. This example demonstrates DAP based on knowledge that objectifies children (Blaise, 2005). This knowledge base excludes the social, cultural, and political construction of children's bodies and the social justice notion of gender beyond biological male or female bodies. The example highlights, through a discourse of heteronormativity, the requirement to separate children using a scale of chronological age and biological sex, implying that sexual play will develop into the next stage of development (Blaise, 2005) by the age of six years. It shows how the regulations work to resolve quandaries around discourses of heterosexual behaviour that might ensue between children's bodies. By ignoring other possible sexual thoughts or behaviours, such as those within a homosexual lens, the regulations regulate children's bodies from a dominant developmental framework that assumes children older than 6 are not trustworthy in overnight situations when they are in the same room as younger children. By naming discourses of heteronormativity, we can question the privilege found within dominant attitudes that gender bodies.

Discourses of mistrust. The regulations lay out other implicit discourses of mistrust around age categories that confirm understandings that a person's age can be a potential threat to a child's body. For example, Section 20.1 states, "The licensee must not permit a person over the age of 12 to be ordinarily present on the premises ... while children are present, unless the person is of good character and the licensee has obtained a criminal record check for that person." This section shapes a discourse of mistrust, implying that once a child is 12 years old, they may no longer be innocent and cannot be trusted in the space of younger children unless they have been deemed safe by a recognized governmental authority such as the local police. Following Millei and Cliff (2014), this hidden discourse brings about visions of young adolescents as objects or agents that threaten programming. This is how the regulations form a binary that younger children are innocent and older children are threatening, which works to resolve threats of potential conflict, such as child molestation, by placing blame on older children. This binary regulates bodies by securing barriers that separate older children, who are seen as potential threats, from younger children, who are understood as innocent and in need of protection. This is how the discourse of mistrust is born 
through the regulations.

Another age category is exemplified in the regulations that creates a discourse of mistrust by positing the definition of a "responsible adult" as age 19 or older. This term hints that people between 12 and 19 are a potential threat to young children. These examples lean on discourses of developmental psychology because they categorize bodies by measuring chronological age on a scale that confirms certainty for discourses of mistrust (Burman, 2008; Dahlberg \& Moss, 2005; MacNaughton, 2005).

Discourses of protection. The regulations regulate bodies by forming various other discourses that begin with the need to protect young children's bodies. For instance, Section 16(4b) conveys implicit messages with respect to play area, materials, and equipment that are based on an assumption that children's bodies are vulnerable. To ensure that children have enough space to play and that anything considered a hazard is removed, this section states that "play materials and equipment accessible to children ... are safely constructed, free from hazards and in good repair." This rule sets up a discourse that children need to live in what Fleer (2003) calls a "child-centered" or "artificial world" (p. 66) to be safe. Safety is often a priority in early childhood education, and therefore good practice connects with safety standards that commonly require children's bodies to be separated from the real or adult world to be protected. Fleer's idea about overprotecting children is highlighted again in Section 15.2(c), which states, "A licensee must ensure that each piece of furniture or equipment for sleeping is appropriate for the size, age and development of the children intended to use it." Underpinning images of children's bodies as small, unknowing, and weak invites a technique of power through discourses that emphasize the relationship between children's bodies and the need for protection from debris or hazards found in the real, or unsafe, world. The regulations therefore regulate children's bodies through the creation and reinforcement of discourses of safety, which create truths about protecting bodies from hazardous equipment. The regulations then work through these discourses to resolve potential safety issues, such as injury, that might arise in the real or adult world, to shield children's bodies from harm.

Through these examples that create and sustain developmental truths, the regulations lay out a framework of hidden discourses for educators and programs to follow that regulate children's bodies through techniques of power.

\section{How does the normalization of bodies take place in the regulations?}

Furthering discussions that show how techniques of power work through the formation of discourses to influence and create knowledge, this section focuses on how the regulations normalize children's bodies. This happens by shaping developmentally appropriate ideas and beliefs that constitute proper health and safety routines, as understood through a Euro-Western cultural lens.

Discourses of Euro-Western culture. The regulations provide a developmental framework that employs powerful techniques that shape cultural discourses to regulate children's bodies in a Euro-Western social context. I found only a hint of difference in culture, context, and choice outside this dominant lens, in Section $48.3 \mathrm{c}$ about food preferences. A focus on Euro-Western preferences brings questions about why other cultural preferences are almost invisible, and why any mention of diversity comes as an afterthought, with no further description. Hidden in the regulations is a lack of cultural diversity when attending to children's bodies in ECE.

From an original purpose of reaching goals of quality care, health, and safety and to provide opportunities for growth, the Child Care Licensing Regulation Information Packet (Government of British Columbia, 2008b) normalizes children's bodies according to a Euro-Western cultural context. However, consultation has moved toward creating a National Food Policy for Canada (2018) that supports collaboration from various groups to 
meet the needs of building food security from diverse cultures and contexts to connect health, environment, and economic growth across the country. This trend leads me to wonder whether it might be possible to align the regulations with current priorities that embrace diversity.

Additionally, the Government of British Columbia's welcome website (2017a) explains that Aboriginal people have lived in what is now known as British Columbia for more than 10,000 years. Aboriginal peoples developed their own policies before European explorers began to arrive in the mid-eighteenth century, bringing with them Chinese migrants to help with conducting the business of fur trading (Government of British Columbia, 2017b) during a time when the province was home to thousands of Aboriginal people. Today there are approximately 200,000 Aboriginal people in British Columbia, making up 198 distinct First Nations groups, each with their own unique traditions and history (Government of British Columbia, 2017a). As Canada's most ethnically diverse province today, British Columbia welcomes nearly 40,000 new immigrants every year (Government of British Columbia, 2017c). Therefore, I wonder how multiculturally diverse families in British Columbia might interpret the regulations in Schedule G.4c, which "encourage the emotional development of children, including providing a comfortable atmosphere in which children feel proud of their cultural heritage and cultural sharing is encouraged" (Schedule G.4c). I believe the regulations impose cultural and contextual difficulties that challenge the way ECE understands and attends to each child's cultural practice. For example, if a child's culture understands sharing a bed as normal (Jiang et al., 2016) and the child prefers to sleep with another child, the regulations provide a challenge because they require sleeping equipment to be "used only by one child at a time" (Section 15.2a). Thus, licensed institutional care programs are kept in check through Euro-Western cultural understandings that view bed sharing as abnormal and problematic. This example highlights how contextual and cultural techniques of power work through the discourses in the regulations to normalize, legitimize, and therefore assimilate bodies by sending messages that bodies are desirable only when they align with sanctioned Euro-Western cultural ideas.

\section{How does the disciplining of bodies take place in the regulations?}

Using MacNaughton's (2005) explanation that discipline works through attitudes of discretion about where, what, and how bodies need to be expressed, this section highlights how the authoritative tone in the regulations works to discipline children's bodies.

I found that the regulations discipline bodies through discourses that socially construct the need for certainty from a polarized position of power. Dahlberg and Moss (2005) describe polarized thinking as setting up opposing sides where one is desired and the other is banished. This dualistic model does not hold well for the child's body that acts or lives outside the majority. If policy is believed to be the reconcilable force that pathologizes (Sukariah \& Tannock, 2015), those bodies that challenge the norm by falling outside of predictable boundaries are seen as needing discipline. I think the idea of privileging some bodies over others lies inside phrases such as "unless the medical health officer is satisfied" (Section 9.2). This phrase gives power to a governmental authority figure who is unfamiliar with the particular context of the program, the culture of its participants, and the social uniqueness of each child, family, and educator. Situated outside the program, the medical health officer holds power through sanctioned regulations, making decisions about which bodies are privileged and which are excluded or pathologized (Fleer, 2003). In this way the regulations discipline bodies through the confirmation of polarized discourses that privilege and pathologize.

Micropractices of power. The regulations' authoritative tone blends ethical substance with a prescriptive vision. Ideas that channel ethical substance into a prescribed way of doing practice invite micropractices of power to work by bringing the regime of truth to life. As mentioned, MacNaughton (2005) describes micropractices, or techniques of power, as working through the supervision and governance of children's bodies in ways that support 
and sanction truths. These truths then work to guide the way we think, do, and live in our practice. An example is found in Section 46.1 of the regulations, which states, "A licensee must establish a program to instruct children in, and to practice the rules of, health and hygiene." This statement builds a micropractice of power with ethical tones through a discourse of best practice that requires educators to teach children's bodies to follow rules of health and hygiene. This specific rule underscores Millei and Cliff's (2014) ideas of how discipline works, by highlighting best practice discourses using an image of children's bodies as needing intervention to ensure health and hygiene.

Discourses of colonizing childhood. Furthering the idea of choosing some bodies over others, Varga (2011) highlights the use of governmental techniques illuminated as discourses in the realm of sociohistorical colonization of children's bodies. As a strategy of power and control utilized by nations over subjugated people, governmental power has been shown to provide historical, racial, and social contexts for understanding and promoting "the advancement of Eurocentric culture through a generic 'White' development" (p. 137). Depending on the priorities and desires of those holding authoritative roles, such as the medical health officer, children's bodies are positioned in a place where they can be appropriated through attitudes about discipline embedded in the regulations. For example, Sections 36(2), 45(4), and 49(1-2) use the term "parent," which privileges the biological, legal, marital, and single-household definition of belonging and holding responsibility for the child's body outside the child care centre. Instead of using family, kinship, or community language, the regulations assume a traditional monoculture, excluding children who are raised beyond one household (Tam, Findlay, \& Kohen, 2017). Another example of colonizing childhoods is found in Section 48.5, which states, "A licensee must ensure that safe drinking water is available to children," yet many First Nations reserves in Canada continue to lack access to safe drinking water due to longstanding inequities (Bradford, Zagozewski, \& Bharadwaj, 2017). This systemic issue works against children's bodies that do not adhere to a solid foundational way of healthy living according to common standards. A final example is shown in Section 57(2) that requires the licensee to obtain records of all relevant matters including sex, participation, and so on for up to five years, which in my interpretation steps into the oversurveillance of bodies. These are some examples of how the regulations put forward discourses that colonize childhood.

Discourses of surveillance. Finally, in connection with discourses of colonizing bodies, I highlight the discursive assumption that "children are supervised at all times by a person who is an educator, an assistant or a responsible adult" (Section 39.1). As a form of surveillance, supervision provides a micropractice of power that works to discipline bodies through a reference of truths that once again resolve issues around what is considered to be normal or abnormal behaviour. Surveillance employs a witness to ensure that bodies act in ways that are considered to be appropriate. The early childhood educator works as a catalyst for disciplining children's bodies through the regime of truth that imagines bodies as needing binaries of totalization, or sameness, through forces of discipline that produce a will to conform (MacNaughton, 2005).

Therefore, the regulations work to discipline children's bodies through entanglements of power that are embedded in the political and ethical substance of a regime of truth. Thus, through the construction of sanctioned discourses, techniques of power allow discipline to work in ways that keep children's bodies in check with developmentally appropriate or best practice through a Euro-Western cultural lens.

\section{Conclusion}

This paper challenged developmentally appropriate practice (DAP) by unpacking British Columbia's Child Care Licensing Regulations (BC Laws, 2016). My critical discourse analysis highlighted dominant discourses relating to children's bodies in the ways of thinking, working, and doing early childhood education, while attending to four questions set out at the beginning of the paper, as follows. 
First, the regulations bring assumptions that children's bodies should be organized by methods of DAP to regulate, normalize, and discipline bodies according to measurements such as the age and developmental stage of the child's body. Using a clear scale of measurement provides certainty so that bodies can be compared and universalized. Appropriate bodies follow Euro-Western health and safety routines, such as those prescribed by the Canada Food Guide. Appropriate bodies are assumed to be those that identify with a heteronormative social construction that shapes gender ideas about bodily behaviour from a single lens connected to biological sex. Good educators are expected to follow quality programming by organizing children's bodies from a DAP model through a EuroWestern framework.

Second, techniques of power work to shape bodies through the discourses of developmental psychology in the regulations by working to control thinking, being, and doing while aligning with sanctioned political intent. By forming systems of truth, dominant power regimes are created which employ developmental discourses. These discourses then become rationalized by the common powers of neoliberalism and governmentality that promote a system of ideas that translate into mechanisms or technologies of practice. These mechanisms bring certainty, often through quantifying bodies toward a desired outcome, while pathologizing opposing outcomes. Thus, regimes of truth work to govern and regulate powerful ideas about bodies.

Third, Euro-Western social, cultural, and contextual conditions are embedded throughout the regulations, prescribing health and safety routines through good/bad binary thinking that promotes high levels of health and safety routines. Cultural diversity is almost completely absent, especially considering the province's incredible diversity. However, some current trends are moving toward collaborative thinking to expand cultural diversity in government policy.

Fourth, the discourses in the regulations work to resolve problems before they might arise. For example, discourses of heteronormativity provide developmentally appropriate thinking instead of complexifying the possibility of other ways of doing gender or sexuality. Separating children according to biological sex is an easy way to resolve conflict from a male/female binary.

Understanding how discourses are formed and how they connect with knowledge is important, because this relationship invites critical reflection that opens multiple conversations that begin to shift common thinking about how to practice ethically with children's bodies, instead of following common prescribed ways of thinking and doing practice.

It is my hope that this analysis will contribute to discussions about children's bodies in early childhood education that move beyond techniques of control, through advocacy and freedom of expression that might emerge from alternative discourses. 


\section{References}

Ashton, E. (2014). I’ve got my EYE on you: Schooled readiness, standardized testing, and developmental surveillance. Canadian Children, 39(1), 3-24. https://doi.org/10.18357/jcs.v39i1.15243

BC Laws. (2016). Community care and assisted living act: Child care licensing regulation. Retrieved from http://www.bclaws.ca/civix/ document/id/complete/statreg/332_2007

Blaise, M. (2005). Playing it straight: Uncovering gender discourses in the early childhood classroom. London, UK: Routledge.

Bradford, L.E.A., Zagozewski, R., \& Bharadwaj, L.A. (2017). Perspectives of water and health using Photovoice with youths living on reserve. The Canadian Geographer / Le Géographe Canadian, 61(2), 178-195. doi:10.1111/cag.12331

British Columbia Director of Licensing Standards of Practice. (2016). Director of licensing standard of practice: Active play. Retrieved from https://www2.gov.bc.ca/assets/gov/health/about-bc-s-health-care-system/child-day-care/active_play_june_2016.pdf

Burke, R. S., \& Duncan, J. (2015). Bodies as sites of cultural reflection. New York, NY: Routledge.

Burman, E. (2008). Deconstructing developmental psychology (2 $2^{\text {nd }}$ ed.). New York, NY: Routledge.

Cannella, G.S. (1997). Deconstructing early childhood education: Social justice and revolution. New York, NY: Peter Lang.

Dahlberg, G., \& Moss, P. (2005). Ethics and politics in early childhood education. New York, NY: Routledge.

Dahlberg, G., Moss, P., \& Pence, A. (2013). Beyond quality in early childhood education and care: Languages of evaluation (3 ${ }^{\text {rd }}$ ed.). London, UK: Routledge.

Fleer, M. (2003). Early childhood educators as an evolving "community of practice" or as lived "social reproduction": Researching the "taken-for-granted." Contemporary Issues in Early Childhood, 4(1), 64-79. https://doi.org/10.2304/ciec.2003.4.1.7

Foucault, M. (1977). Truth and power. In C. Gordon (Ed.), Power/knowledge: Selected interviews and other writings $1972-1977$ (pp. 109-133). Sussex, UK: The Harvester Press.

Foucault, M. (1978). The history of sexuality: An introduction. New York, NY: Vintage.

Foucault, M. (1984). On the genealogy of ethics: An overview of work in progress. In P. Rabinow (Ed.), The Foucault reader. Harmondsworth, UK: Penguin.

Foucault, M. (1995). Discipline and punish: The birth of the prison (A. Sheridan, Trans.). New York, NY: Vintage Books. (Original work published 1975)

Government of British Columbia. (2008a). British Columbia early learning framework. Victoria, BC: Ministry of Education, Ministry of Children and Family Development, Early Learning Advisory Group, \& Ministry of Health.

Government of British Columbia. (2008b). Child care licensing regulation: Information package. Retrieved from http://www.health.gov. bc.ca/library/publications/year/2008/Child_Care_Licensing_Regulation.pdf

Government of British Columbia. (2017a). First Nations Aboriginal people. Retrieved from https://www.welcomebc.ca/Choose-B-C/ Explore-British-Columbia/B-C-First-Nations-Aboriginal-People

Government of British Columbia. (2017b). Chinese arrive in Canada. Retrieved from http://www2.gov.bc.ca/gov/content/governments/ multiculturalism-anti-racism/chinese-legacy-bc/history/first-arrivals

Government of British Columbia. (2017c). Multiculturalism and anti-racism. Retrieved from http://www2.gov.bc.ca/gov/content/ governments/multiculturalism-antiracism

Government of Canada. (2018). What we heard: A food policy for Canada consultations. Minister of Agriculture and Agri-Food. Retrieved from https://www.canada.ca/content/dam/aafc-aac/documtnes/20180904-en.pdf

Health Canada. (2016). Canada's food guide. Retrieved from https://www.canada.ca/en/health-canada/services/canada-food-guides.html 
HealthLinkBC. (2016). Growth and development milestones. Retrieved from https://www.healthlinkbc.ca/health-topics/abo8756

Jiang, Y., Chen, W., Spruyt, K., Sun, Wand, Y., Li, S. Shen, X. Wang, G. \& Jiang, F. (2016). Bed-sharing and related factors in early adolescents. Sleep Medicine, 17, 75-80. doi:10.1016/j.sleep.2015.08.022

Kessler, S., \& Swadener, B.B. (Eds.). (1992). Reconceptualizing the early childhood curriculum: Beginning the dialogue. New York, NY: Teachers College Press.

KSI Research International. (2017). Leading informed practice. Retrieved from http://ksiresearch.com/

MacNaughton, G. (2005). Doing Foucault in early childhood studies. New York, NY: Routledge.

MacNaughton, G., Hughes, P., \& Smith, K. (2007). Rethinking approaches to working with children who challenge: Action learning for emancipatory practice. International Journal of Early Childhood, 39(39), 39-57. doi:10.1007/BF03165947

Millei, Z., \& Cliff, K. (2014). The preschool bathroom: Making "problem bodies" and the limit of the disciplinary regime over children. British Journal of Sociology of Education, 35(2), 244-262. doi: 10.1080/01425692.2012.761394

Moss, P. (2014). Transformative change and real utopias in early childhood education: A story of democracy, experimentation, and potentiality. New York, NY: Routledge.

Moss, P., \& Petrie, P. (2002). From children's services to children's spaces. New York, NY: Routledge.

Pacini-Ketchabaw, V. (2005). The meanings embedded within childcare regulations: A historical analysis. Contemporary Issues in Early Childhood, 6(1), 41-53. https://doi.org/10.2304/ciec.2005.6.1.8

Pacini-Ketchabaw, V., Nxumalo, F., Kocher, L., Elliot, E., \& Sanchez, A. (2015). Journeys: Reconceptualizing early childhood practices through pedagogical narrations. North York, ON: University of Toronto Press.

Sevenhuijsen, S. (1998). Citizenship and the ethics of care: Feminist considerations on justice, morality, and politics. New York, NY: Routledge.

Sukariah, M., \& Tannock, S. (2015). The neoliberal embrace of youth: Youth rising? In The politics of youth in the global economy (pp. 12-32). New York, NY: Routledge.

Tam, B.Y., Findlay, L.C., \& Kohen, D.E. (2017). Indigenous families: Who do you call family? Journal of Family Studies, 23(3), $243-259$. doi:10.10/8013229400.2015.1093536

Varga, D. (2011). Look-normal: The colonized child of developmental science. History of Psychology, 14(2), 137-157. doi:10.1037/ a0021775 